\title{
Assessment of left ventricular longitudinal function in cats with subclinical hypertrophic cardiomyopathy using tissue Doppler imaging and speckle tracking echocardiography
}

\author{
Keisuke SUGIMOTO ${ }^{1)}$, Yoko FUJII ${ }^{1) *}$, Hiroshi SUNAHARA ${ }^{1)}$ and Takuma AOKI ${ }^{1)}$ \\ 1)Laboratory of Surgery 1, Azabu University, 1-17-71 Fuchinobe, Chuo-ku, Sagamihara-shi, Kanagawa 252-5201, Japan
}

(Received 10 July 2014/Accepted 3 April 2015/Published online in J-STAGE 16 April 2015)

\begin{abstract}
Hypertrophic cardiomyopathy (HCM) in cats is characterized by concentric left ventricular (LV) hypertrophy and both diastolic and systolic dysfunction. Although impaired cardiac function detected by tissue Doppler imaging (TDI) in cats with HCM was previously reported, reference ranges of TDI in normal cats and cats with HCM have been reported as widely variable. Two-dimensional speckle tracking echocardiography (STE) was useful for assessment of cardiac function in human patients with HCM, but clinical utility was not known in cats. The aim of this study was to assess global and segmental LV myocardial function using STE in cats with HCM whose TDI variables were within the reference range. A total of 35 cats of different breeds were enrolled in this study. The HCM group ( $\mathrm{n}=22$ ) was cats diagnosed as HCM without left atrial enlargement and with normal TDI measurements. HCM cats were further divided into a segmental hypertrophy (S-HCM) group and a diffuse hypertrophy (D-HCM) group. The control group consisted of 13 clinically healthy cats. No cats in any group showed any clinical symptoms. Conventional echocardiography, TDI, and global and segmental STE indices were evaluated and compared between groups. Only the longitudinal strain rate during early diastole was significantly decreased in both HCM groups, even in all segments including those without hypertrophy in S-HCM group. This study suggests that STE parameters are the more sensitive variables compared with conventional TDI parameters to detect early myocardial diastolic dysfunction in cats with HCM.

KEY WORDS: cardiomyopathy, feline, speckle tracking echocardiography, strain, tissue Doppler imaging
\end{abstract}

doi: 10.1292/jvms.14-0354; J. Vet. Med. Sci. 77(9): 1101-1108, 2015

Hypertrophic cardiomyopathy (HCM) is the most common heart disease in cats [21, 37] and is characterized by concentric left ventricular (LV) hypertrophy and both diastolic and systolic dysfunction. Diastolic dysfunction leads to left atrial (LA) enlargement and subsequent congestive heart failure. Systolic dysfunction occurs with the progressive disease process [47]. Cats in the early stage of HCM are asymptomatic [45], although myocardial dysfunction can occur with disease progression $[1,29]$.

Diastolic dysfunction is considered to be a primary abnormality of the disease [23, 29], and evidence for this has been provided by both invasive and noninvasive studies [4, 25]. Systolic dysfunction also occurs probably due to pathologic fibrosis and increased matrix connective tissue [22, 47]. Although both short- and long-axis strains were reported to be depressed in human patients with HCM [5, 28], several studies indicated that longitudinal strain parameters were significantly affected, and a similar finding was reported in cats with HCM [31].

Tissue Doppler imaging (TDI) allows non-invasive assessment of myocardial function and has demonstrated segmental and global myocardial dysfunction in cats with

*Correspondence to: FujiI, Y., Laboratory of Surgery 1, Azabu University, 1-17-71 Fuchinobe, Chuo-ku, Sagamihara-shi, Kanagawa 252-5201, Japan.e-mail: fujiiy@azabu-u.ac.jp

(C)2015 The Japanese Society of Veterinary Science

This is an open-access article distributed under the terms of the Creative Commons Attribution Non-Commercial No Derivatives (by-nc-nd) License $<$ http://creativecommons.org/licenses/by-nc-nd/3.0/>.
$\operatorname{HCM}[7,9,12,16,17,27,31,42]$. The longitudinal velocity profiles include peak systolic myocardial velocities (s') and peak early diastolic myocardial velocities at the mitral annulus (e') [16, 27, 44]. Previous studies have reported that s' or e' in LV free wall and interventricular septum (IVS) are reduced in cats with HCM. However, TDI is angle dependent [46], and the reported reference ranges for TDI in normal cats (s'; 1.9-8.7 m/sec, e'; 2.2-10.2 m/sec) [4, 7, 9, $12,16,17,27,31,42]$ and cats with HCM (s'; 0.5-6.0 m/ sec, e'; 0.6-5.4 m/sec) [7, 9, 27, 31, 42] are highly variable.

Two-dimensional speckle tracking echocardiography (STE) is a relatively new approach designed to assess ventricular function. STE has no angle-dependence and allows the assessment of any segment of the heart [3]. Some longitudinal STE parameters have been shown to correlate with MRI and pathological findings [30, 38]. The usefulness of STE analysis for assessment of cardiac function in human patients with HCM [5, 6, 24, 40], dogs with cardiomyopathies $[10,11,48]$ and healthy cats $[41]$ has been reported.

We hypothesized that STE analysis is a more sensitive technique to evaluate early myocardial impairment compared with TDI and can detect myocardial dysfunction in the subclinical HCM when TDI variables were still within the normal reference range. The aim of this study was to assess global and segmental LV longitudinal function using STE in cats with HCM whose TDI variables were within the reference range. 


\section{MATERIALS AND METHODS}

Animals: Study groups consisted of 22 cats with HCM and 13 clinically healthy cats (control group). Cats with HCM were prospectively recruited from patients presented to Azabu University Veterinary Teaching Hospital, because of suspected cardiac disease from April 2012 to January 2014.

The HCM group included cats diagnosed as HCM without left atrial enlargement (the left atrium-to-aortic root (LA/Ao $<1.5)$ [26] and with normal TDI variables. Cats in the control group were either client-owned $(n=3)$ or experimental cats $(n=10)$ determined to be clinically healthy on the basis of clinical history, physical examination, blood pressure measurement, conventional echocardiographic examination, thoracic radiographs, $\mathrm{CBC}$ and serum chemistry panels. No cats in either group showed any clinical signs. None of the cats in either group were receiving treatment or medication at the time of enrollment into the study.

Echocardiographic examination: All echocardiographic images were acquired using an ultrasound unit equipped with a $7 \mathrm{MHz}$ and $10 \mathrm{MHz}$ transducer (Vivid 7 dimension, GE Medical System, Tokyo, Japan). Echocardiographic examination was performed by three sonographers (KS, YF and TA). All echocardiographic measurements were directly performed on the screen freeze-frame images, and then, 3 consecutive measurements were averaged for each value. Cats were gently restrained in lateral recumbency. The aortic and left atrial diameters at the end-systole and LA/Ao were measured from the right-sided parasternal short-axis view at the level of the aortic valve using a 2-dimensional method as previously described and validated [14, 43]. Left ventricular internal diameters (LVIDd), IVS and LV free wall thickness at the end-diastole (IVSd and LVFWd, respectively) were measured from the right parasternal short-axis view at the level of the chordae tendineae, and the LV shortening fraction (FS) was then calculated. The sub-aortic IVS thickness was measured at the end-diastole from the right parasternal 5-chamber view. Heart rate (HR) was calculated from M-mode images.

HCM was determined when the IVSd and/or LVFWd was $6 \mathrm{~mm}$ or more on the M-mode echocardiographic examination and the right parasternal long-axis view in the absence of pressure overload and systemic diseases known to cause LV hypertrophy [23]. LV thickness was measured at least in 4 left ventricular sites from the short axis view [37], and the mean value of 3 consecutive beats of the thickest segment among measured ventricular sites (LVTSd) was calculated. HCM cats were divided into 2 groups; HCM with segmental hypertrophy (S-HCM group) and diffuse hypertrophy (D-HCM group). S-HCM was defined as when hypertrophy was seen in $50 \%$ or more of the LV region, but the whole region was not thickened. D-HCM was defined as when the whole LV regional was hypertrophied [37]. Continuous-wave Doppler was used to measure maximal systolic left ventricular out flow tract velocity to confirm an LV outflow obstruction characterized by turbulent aortic flow of high velocity ( $>2 \mathrm{~m} / \mathrm{s}$ ) [13].

Tissue Doppler imaging: All color TDI examinations were performed as previously described [27]. The septal and lateral aspects of the mitral annulus were sampled using the left 4-chamber apical view. A $2 \times 2 \mathrm{~mm}$ sample without angle correction was used. The mean value in 3 consecutive cardiac cycles in a single cine loop was used for statistical analysis. The normal reference range of s' was defined as greater than $6 \mathrm{~cm} / \mathrm{sec}$, and that of e' was defined as greater than $5.4 \mathrm{~cm} / \mathrm{sec}$ based on previous reports $[4,7,9,12,16$, 17, 27, 31, 42].

Speckle tracking echocardiography: Longitudinal strain and strain rate were determined from the left apical fourchamber view. The frame rate used for this study to analyze STE indices ranged from 100 to 155 frames per second. Images were acquired from cine loops triggered by the QRS complex, and off-line image analysis was performed using commercial software (EchoPAC PC, GE Medical System, Tokyo, Japan). The principle of speckle tracking analysis was described in previous studies [19, 41, 47, 49]. Endocardial borders in the end-systolic frame of the 2-D images were manually traced to measure the left ventricular internal diameter at end systole. In S-HCM group, regions of interest were adjusted to LVFW that were not hypertrophied. The computer software automatically tracked myocardial motion and created 6 regions of interest in each image (baseseptum, middleseptum, apicalseptum, apicallateral, middlelateral and baselateral). The tracking quality of myocardial motion was automatically evaluated by the computer software to determine whether it was reliable, and the quality was expressed as valid or failed. When the computer software indicated the tracking had failed, the observer re-traced the endomyocardium until the quality was expressed as valid. The cardiac cycles used for analyses were determined by a simultaneous ECG (from R to R wave).

Peak longitudinal systolic strain (SL) and peak longitudinal strain rate during systole and early diastole (SrLs and SrLe) were measured in 6 segments from the basal, middle and apical regions of the septal and lateral walls (Fig. 1). Global values represent the average measurements from these 6 ventricular segments. The global peak longitudinal strain rate during late diastole (SrLa) was also measured, and SrLe/SrLa was calculated. STE parameters were calculated from three consecutive cardiac cycles on the same frame, and the mean value was used for analysis.

Statistical analyses: All measurements were expressed as mean \pm SD. All analyses were performed by one observer (KS). Statistical analyses were performed using computer software (SPSS Statistics version 21.0, Chicago, IL, U.S.A.). All echocardiographic data were visually inspected and tested for normality by the Kolmogorov-Smirnov test. Comparisons for age, body weight and echocardiographic data among the 3 groups were performed using one-way analysis of variance. When normality was rejected, the Kruskal-Wallis test was used. Gender among groups was assessed by $\chi^{2}$ test. When a significant difference was detected, multiple comparisons were evaluated by use of Bonferroni correction. In the S-HCM and D-HCM groups, correlations between following parameters were examined by use of Spearman's rank correlation coefficient; global values of STE parameters vs. IVSd or LVFWd, mean values of STE parameters in 3 segments of IVS or LVFW vs. 


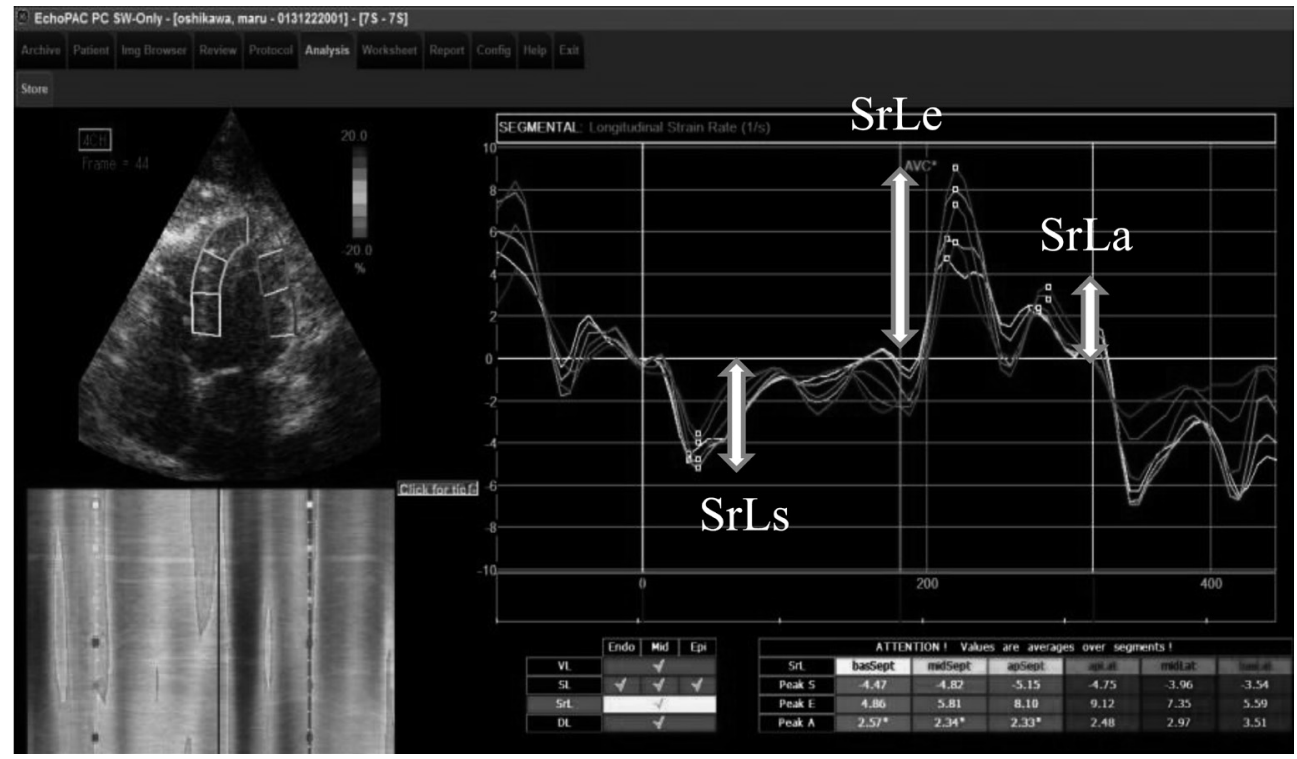

Fig. 1. Longitudinal strain rate tracking for one cardiac cycle obtained from the left 4-chamber apical view. Six curves with different colors depict respective myocardial segments of left ventricle (basal, middle and apical regions of the septal and lateral). Systolic and early diastolic values of longitudinal strain rate (SrLs, SrLe and SrLa) were calculated.

Table 1. Characteristics of S-HCM, D-HCM and control groups

\begin{tabular}{cccccc}
\hline Index & Unit & Control Group & S-HCM Group & D-HCM Group & $P$ value \\
\hline $\begin{array}{c}\text { Number } \\
\text { Gender }\end{array}$ & F/M & 13 & 17 & 5 & NS \\
Age & months & $5 / 8$ & $6 / 11$ & & NS \\
& Mean \pm SD & $39.2 \pm 36.4$ & $38.9 \pm 31.4$ & $45.6 \pm 17.2$ & $24-73$ \\
Range & $7-110$ & $6-108$ & $4.08 \pm 1.10$ & NS \\
Body Weight & $\mathrm{kg}$ & $3.92 \pm 0.83$ & $3.97 \pm 1.91$ & Scottish Fold 1 & American Shorthair 1 \\
Breeds & & Norwegian Forest Cat 2 & Scottish Fold 4 & Maine Coon 1 \\
& & Domestic Shorthair 11 & American Shorthair 3 & Maine Coon 1 & Domestic Shorthair 2 \\
& & Exotic Shorthair 1 & & \\
& & Ragamuffin 1 &
\end{tabular}

NS: Not significant.

IVSd or LVFWd. Intraobserver variability for each global STE parameter was assessed by calculation of coefficients of variation $(\mathrm{CV})$ using the formula: $\mathrm{CV}=(\mathrm{SD} /$ arithemic mean of measurements $) \times 100$ [15]. Coefficients of variations were considered clinically acceptable if $<10 \%$ [27].

\section{RESULTS}

Animals: The characteristics of all groups are shown in Table 1. S-HCM group and D-HCM group included 17 and 5 cats, respectively. IVS hypertrophy without LV free wall hypertrophy was seen in all cats included in S-HCM group. In S-HCM and D-HCM groups, 17 and 4 cats showed dynamic LV outflow obstruction due to SAM, respectively.
Echocardiography examination: The results of conventional echocardiography are shown in Table 2. Those IVSd, LVFWd, LVTSd, FS and aortic flow of high velocity were significantly higher, and LVIDd was significantly lower in both HCM groups than in the control group (both $P<0.05$ ). There was no significant difference in HR and LA/Ao. In $\mathrm{S}-\mathrm{HCM}$ and D-HCM groups, the maximum wall thicknesses at end-diastole ranged from 6.0 to $8.2 \mathrm{~mm}$.

TDI: TDI could be assessed in all cats without summation of the e' and late diastolic myocardial velocities. The results of TDI are shown in Table 2. There were no significant differences in s' and e' among 3 groups.

STE: STE was assessed in all cats without summation of e wave and a wave. Table 3 shows the results of global 
Table 2. Results of conventional echocardiography and TDI parameters

\begin{tabular}{llcccc}
\hline & Unit & Control group & S-HCM Group & D-HCM Group & $P$ value \\
\hline LVIDd & $\mathrm{cm}$ & $1.60 \pm 0.10$ & $1.43 \pm 0.20^{*}$ & $1.40 \pm 0.20^{*}$ & 0.007 \\
IVSd & $\mathrm{cm}$ & $0.40 \pm 0.03$ & $0.62 \pm 0.05^{* *}$ & $0.73 \pm 0.06^{* * \dagger}$ & $<0.001$ \\
LVFWd & $\mathrm{cm}$ & $0.40 \pm 0.04$ & $0.44 \pm 0.05^{*}$ & $0.65 \pm 0.08^{* * \dagger}$ & $<0.001$ \\
FS & $\%$ & $40.7 \pm 7.5$ & $60.3 \pm 10.2^{* *}$ & $60.1 \pm 10.9^{* *}$ & 0.002 \\
LA/Ao & & $1.21 \pm 0.14$ & $1.22 \pm 0.10$ & $1.23 \pm 0.11$ & $\mathrm{NS}$ \\
aortic flow of high velocity & $\mathrm{m} / \mathrm{sec}$ & $0.98 \pm 0.20$ & $3.22 \pm 1.05^{* *}$ & $2.90 \pm 1.26^{* *}$ & $<0.001$ \\
LVTSd & $\mathrm{cm}$ & $0.42 \pm 0.05$ & $0.63 \pm 0.25^{* *}$ & $0.67 \pm 0.46^{* *}$ & $<0.001$ \\
HR & $\mathrm{bpm}$ & $165 \pm 39$ & $178 \pm 29$ & $168 \pm 10$ & $\mathrm{NS}$ \\
$\mathrm{s}^{\prime}$ (Lateral) & $\mathrm{cm} / \mathrm{sec}$ & $7.30 \pm 0.70$ & $7.38 \pm 0.89$ & $7.42 \pm 0.98$ & $\mathrm{NS}$ \\
$\mathrm{s}^{\prime}$ (Septal) & $\mathrm{cm} / \mathrm{sec}$ & $7.12 \pm 0.66$ & $7.33 \pm 0.54$ & $7.00 \pm 1.18$ & $\mathrm{NS}$ \\
$\mathrm{e}^{\prime}$ (Lateral) & $\mathrm{cm} / \mathrm{sec}$ & $8.70 \pm 1.88$ & $8.78 \pm 2.02$ & $8.73 \pm 1.17$ & $\mathrm{NS}$ \\
$\mathrm{e}^{\prime}$ (Septal) & $\mathrm{cm} / \mathrm{sec}$ & $6.95 \pm 1.05$ & $6.90 \pm 0.99$ & $7.00 \pm 0.71$ & $\mathrm{NS}$ \\
\hline
\end{tabular}

LVIDd: Left ventricular internal diameters at end-diastole; IVSd: Interventricular septum wall diameters at end-diastole; LVFWd: Left ventricular free wall diameters at end-diastole; FS: Left ventricular shortening fraction; LA/Ao: Left atriumto-aorta ratio; LVSTd: Left ventricular thickest segment diameters at end-diastole; HR: Heart Rate; s' (Lateral): Peak systolic myocardial velocities at mitral annulus of lateral aspect; s' (Septal): Peak systolic myocardial velocities at mitral annulus of septal aspect; e' (Lateral): Peak early diastolic myocardial velocities at mitral annulus of lateral aspect; e'(Septal): Peak early diastolic myocardial velocities at mitral annulus of septal aspect; NS: Not significant. *: Significant difference compared with control group by multiple comparison $(P<0.05)$. **: Significant difference compared with control group by multiple comparison $(P<0.01)$. $\uparrow$ : Significant difference compared with S-HCM group by multiple comparison $(P<0.01)$.

Table 3. Results of global values in the STE parameters

\begin{tabular}{llcccc}
\hline & Unit & Control group & S-HCM group & D-HCM group & $P$ value \\
\hline SL & $\%$ & $-24.6 \pm 2.6$ & $-23.2 \pm 2.9$ & $-23.5 \pm 3.1$ & NS \\
SrLs & $/ \mathrm{sec}$ & $-3.50 \pm 0.46$ & $-3.36 \pm 0.56$ & $-3.49 \pm 0.57$ & $\mathrm{NS}$ \\
$\mathrm{SrLe}$ & $/ \mathrm{sec}$ & $5.07 \pm 0.96$ & $3.34 \pm 0.49^{* *}$ & $3.30 \pm 0.39^{* *}$ & $<0.001$ \\
$\mathrm{SrLa}$ & $/ \mathrm{sec}$ & $3.08 \pm 0.25$ & $2.12 \pm 0.55^{* *}$ & $2.10 \pm 0.49^{* *}$ & $<0.001$ \\
$\mathrm{SrLe} / \mathrm{SrLa}$ & & $1.65 \pm 0.31$ & $1.66 \pm 0.40$ & $1.65 \pm 0.37$ & $\mathrm{NS}$ \\
\hline
\end{tabular}

SL: Peak systolic longitudinal strain; SrLs: Peak longitudinal strain rate during systole; SrLe: Peak longitudinal strain rate during early diastole; SrLa: Peak longitudinal strain rate during late diastole; NS: Not significant. **: Significant difference compared with control group by multiple comparison $(P<0.01)$.

values in the STE indices of all groups. SrLe and SrLa showed significant differences between control and S-HCM groups $(P<0.001)$, and between control and D-HCM groups $(P<0.001)$. There was no significant difference in SrLe/SrLa among 3 groups. Table 4 showed the results of segmental values in the STE indices of all groups. SrLe in all segments was significantly decreased in both HCM groups in comparison with the control group $(P<0.01)$. SrLe in all segments including those without hypertrophy was also decreased in S-HCM group. Median and interquartile ranges of global and segmental values of SrLe in all groups are shown in Figs. 2 and 3.

Intraobserver variability of STE indices was $4.98 \%$ in SL, $3.55 \%$ in SrLs, $4.40 \%$ in SrLe and 3.89\% in SrLa. CVs in all parameters were considered low.

There were no significant correlations between STE parameters (global values of STE parameters, mean values in 3 segments of IVS and mean values in 3 segments of LVFW) and end-diastolic wall thickness (IVSd and LVFWd) $(P>0.05)$.

\section{DISCUSSION}

The present study revealed that global and segmental SrLe were significantly decreased in HCM cats with normal TDI parameters, and SrLe decreased even in the segments that were not hypertrophied in S-HCM group. Since CVs were considered low in the present study as well as a previous study [41], STE analysis can be applicable for the assessment of cardiac function in cats.

A previous study assessed strain parameters measured by color TDI, which was different from our method, in cats with HCM [47]. TDI has major disadvantages, including angle dependence, limited spatial resolution and deformation analysis (only allowed in one dimension). TDI is the method that assesses cardiac function in a focal area. STE is a novel technique that evaluates left ventricular function more objectively and quantitatively and does not have the limitations seen in TDI [33]. STE also allows the segmental assessment of the heart. STE parameters would be considered a more sensitive technique compared with conventional TDI parameters to detect early myocardial diastolic dysfunction in this population.

In the present study, diastolic myocardial dysfunction was observed in LV free wall segments that were not hypertrophied. Previous studies also indicated that myocardial relaxation was reduced in the segments that were not yet hypertrophied in human, rabbits and cats $[8,9,32,35,36]$. 
Table 4. Results of segmental values in STE parameters

\begin{tabular}{|c|c|c|c|c|c|c|}
\hline & Unit & & Control group & S-HCM group & D-HCM group & $P$ value \\
\hline \multirow{6}{*}{ SL } & \multirow{6}{*}{$\%$} & basSept & $-24.3 \pm 4.1$ & $-23.3 \pm 5.1$ & $-23.5 \pm 6.9$ & NS \\
\hline & & midSept & $-26.6 \pm 3.5$ & $-24.9 \pm 4.1$ & $-25.4 \pm 4.3$ & NS \\
\hline & & apSept & $-26.3 \pm 3.5$ & $-26.2 \pm 3.7$ & $-27.2 \pm 2.0$ & NS \\
\hline & & apLat & $-28.0 \pm 3.9$ & $-25.6 \pm 4.5$ & $-25.1 \pm 2.9$ & NS \\
\hline & & midLat & $-22.6 \pm 3.2$ & $-21.5 \pm 3.4$ & $-21.1 \pm 3.6$ & NS \\
\hline & & basLat & $-19.8 \pm 4.0$ & $-17.9 \pm 3.4$ & $-18.6 \pm 3.9$ & NS \\
\hline \multirow{6}{*}{ SrLs } & \multirow{6}{*}{$/ \mathrm{sec}$} & basSept & $-3.20 \pm 0.92$ & $-3.10 \pm 0.68$ & $-3.00 \pm 1.64$ & NS \\
\hline & & midSept & $-3.65 \pm 0.70$ & $-3.42 \pm 0.55$ & $-3.32 \pm 0.72$ & NS \\
\hline & & apSept & $-4.10 \pm 0.36$ & $-3.78 \pm 0.67$ & $-4.12 \pm 0.54$ & NS \\
\hline & & apLat & $-4.00 \pm 0.36$ & $-3.80 \pm 0.78$ & $-4.15 \pm 0.56$ & NS \\
\hline & & midLat & $-3.27 \pm 0.59$ & $-3.18 \pm 0.72$ & $-3.24 \pm 0.58$ & NS \\
\hline & & basLat & $-2.78 \pm 0.71$ & $-2.89 \pm 0.69$ & $-3.12 \pm 0.39$ & NS \\
\hline \multirow{6}{*}{ SrLe } & \multirow{6}{*}{$/ \mathrm{sec}$} & basSept & $4.02 \pm 1.15$ & $2.63 \pm 0.76^{* *}$ & $2.65 \pm 0.67^{*}$ & 0.001 \\
\hline & & midSept & $4.66 \pm 0.96$ & $3.05 \pm 0.70 * *$ & $3.39 \pm 0.56^{*}$ & $<0.001$ \\
\hline & & apSept & $6.22 \pm 1.07$ & $4.04 \pm 0.83 * *$ & $3.77 \pm 0.38 * *$ & $<0.001$ \\
\hline & & apLat & $6.28 \pm 1.13$ & $4.16 \pm 1.04 * *$ & $3.90 \pm 0.27 * *$ & $<0.001$ \\
\hline & & midLat & $4.94 \pm 1.46$ & $3.37 \pm 0.76^{* *}$ & $3.53 \pm 0.52 *$ & 0.002 \\
\hline & & basLat & $4.49 \pm 1.47$ & $2.78 \pm 0.64^{* *}$ & $3.05 \pm 0.63^{*}$ & $<0.001$ \\
\hline \multirow{6}{*}{ SrLa } & \multirow{6}{*}{$/ \mathrm{sec}$} & basSept & $2.93 \pm 0.21$ & $2.04 \pm 0.54 * *$ & $2.00 \pm 0.32 * *$ & $<0.001$ \\
\hline & & midSept & $3.05 \pm 0.21$ & $2.15 \pm 0.61 * *$ & $2.20 \pm 0.69 *$ & $<0.001$ \\
\hline & & apSept & $2.88 \pm 0.22$ & $2.10 \pm 0.61 * *$ & $2.10 \pm 0.28 *$ & $<0.001$ \\
\hline & & apLat & $3.13 \pm 0.22$ & $2.11 \pm 0.56^{* *}$ & $2.10 \pm 0.74 * *$ & $<0.001$ \\
\hline & & midLat & $2.97 \pm 0.21$ & $2.15 \pm 0.62 * *$ & $2.02 \pm 0.37 *$ & $<0.001$ \\
\hline & & basLat & $3.00 \pm 0.21$ & $2.10 \pm 0.63^{* *}$ & $2.18 \pm 0.67 * *$ & $<0.001$ \\
\hline
\end{tabular}

SL: Peak systolic longitudinal strain; SrLs: Peak longitudinal strain rate during systole; SrLe: Peak longitudinal strain rate during diastole; midSept: Middleseptum; apSept: Apicalseptum; apLat: Apicallateral; midLat: Middlelateral; basLat: Baselateral; NS: Not significant. *: Significant difference compared with control group by multiple comparison $(P<0.05) * *$ : Significant difference compared with control group by multiple comparison $(P<0.01)$

Longitudinal strain rate during early diastole

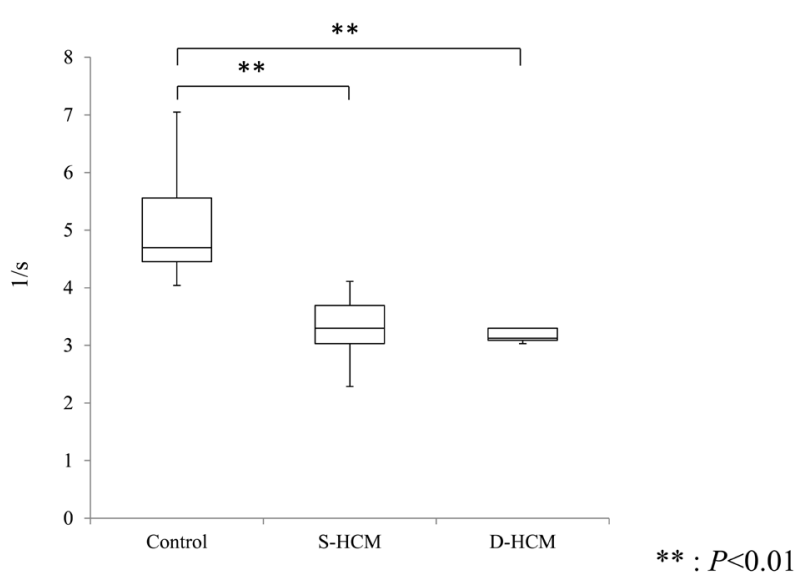

Fig. 2. Boxplot comparing global SrLe. The boxes represent the interquartile ranges. Horizontal bar represents the median value for all groups. SrLe significantly decreased in S-HCM and D-HCM groups in comparison with the control group. ${ }^{* *} P<0.01$.

Nagueh et al. speculated that myocardial dysfunction prior to LV hypertrophy might provide the stimulus for the devel- opment of LV hypertrophy. Chetboul et al. and MacDonald et al. reported that reduced diastolic function was observed in Maine Coon cats before development of LV hypertrophy. However, their case/case series were all single breeds, and no hypertrophy has occurred in LV yet, which was different from our case series. Our results suggested that LV with normal thickness in HCM cats did not always relate to normal segmental myocardial function.

Although SL has been reported to decrease with progressive LV concentric hypertrophy [47], it was not significantly changed in the present study. This discrepancy in the results could be partly due to the difference in the stages of disease and the ages of the populations. A previous report indicated that systolic dysfunction deteriorated as disease progressed [47]. Since all cats in the HCM group in the present study showed no left atrial enlargement, which was considered in the early stage of HCM, systolic function was presumably preserved. An association between aging and systolic function was previously reported in cats [7, 31]. A relationship between aging and myocardial pathologic progression was also previously described [1]. Since our cases consisted of relatively young cats and the disease was in the early stage, systolic function was considered still preserved.

There was no significant difference in SrLe/SrLa among groups in the present study. Baktir et al. described early 

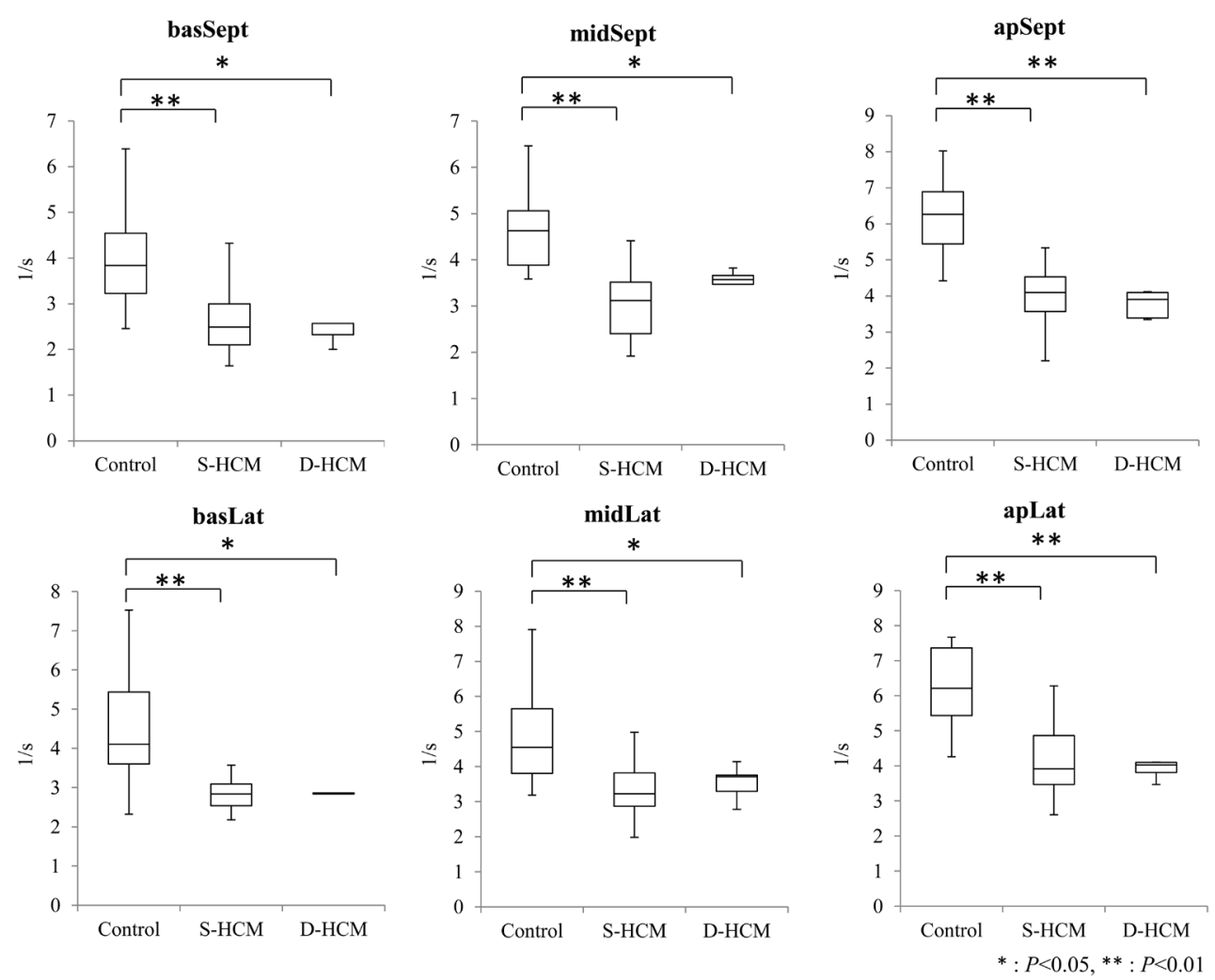

Fig. 3. Segmental SrLe values in normal and HCM groups. The boxes represent the interquartile ranges. Horizontal bar represents the median value for each group. SrLe significantly decreased in all segments in S-HCM and D-HCM groups, compared with the control group. basSept: Baseseptum; midSept: Middleseptum; apSept: Apicalseptum; apLat: Apicallateral; midLat: Middlelateral; basalt: Baselateral. $* * P<0.01$.

diastolic dysfunction in human patients with non-alcoholic steatohepatitis using STE and found the decreased SrLe and SrLa with normal SrLe/SrLa in longitudinal images [2]. Although underlying heart disease was different from our study, their results were similar to ours.

Several previous reports indicated that e' in the LV free wall and IVS decreased in cats with HCM in comparison with normal cats $[7,27,31]$. The previous literature included HCM with congestive heart failure, and the cats were on some medications. Cats in HCM group in the present study were considered to be at a much earlier disease stage than previously reported cats with HCM, since there were no significant differences in TDI parameters.

Saito et al. and Popovic et al. reported that the LV wall thickness may not reflect the severity of myocardial fibrosis, but that strain reflects the severity of fibrosis in human patients with HCM $[38,39]$. Correia et al. and Kobayashi et al. reported that myocardial strain was influenced by a methodology to determine LV regional function as well as myocyte disarray and myocardial fibrosis $[18,30]$. The present study demonstrated that STE parameters were decreased in non-hypertrophied LVFW and there were no significant correlations between STE and LV wall thickness. Abnormal STE parameters may imply some degree of myocardial fibrosis, although a further study is warranted.
There are over 4 limitations in the present study. First, the number of cats available for both groups was limited. Second, both groups consisted of several feline breeds, and the breed might interact with echocardiographic parameters [20, 34]. Different breeds may carry different HCM-associated genes, which could demonstrate different functional manifestations although not known. Third, no blinding process was used for data analyses. Fourth, pathological examination was not available. Finally, we did not compare STE and TDI in the radial and circumferential direction, and did not assess twist nor torsion. A further study is warranted to assess the relevance.

The present study suggests that STE parameters were sensitive variables to detect early myocardial diastolic dysfunction in cats with HCM. In addition to genetic screening, echocardiographic preclinical diagnosis using STE would afford the opportunity to prevent development of LV hypertrophy with early drug therapy in the future and to avoid unfavorable breeding programs.

\section{REFERENCES}

1. Abbott, J. A. 2010. Feline hypertrophic cardiomyopathy: an update. Vet. Clin. North Am. Small Anim. Pract. 40: 685-700. [Medline] [CrossRef]

2. Baktir, A. O., Sarli, B., Altekin, R. E., Karaman, A., Arinc, H., 
Saglam, H., Dogan, Y., Erden, A. and Karaman, H. 2015. Non alcoholic steatohepatitis is associated with subclinical impairment in left ventricular function measured by speckle tracking echocardiography. Anatol. J. Cardiol. 15: 137-142. [Medline] [CrossRef]

3. Biswas, M., Sudhakar, S., Nanda, N. C., Buckberg, G., Pradhan, M., Roomi, A. U., Gorissen, W. and Houle, H. 2013. Two- and three-dimensional speckle tracking echocardiography: clinical applications and future directions. Echocardiography 30: 88-105. [Medline] [CrossRef]

4. Bright, J. M., Herrtage, M. E. and Schneider, J. F. 1999. Pulsed Doppler assessment of left ventricular diastolic function in normal and cardiomyopathic cats. J. Am. Anim. Hosp. Assoc. 35: 285-291. [Medline] [CrossRef]

5. Butz, T., van Buuren, F., Mellwig, K. P., Langer, C., Plehn, G., Meissner, A., Trappe, H. J., Horstkotte, D. and Faber, L. 2011. Two-dimensional strain analysis of the global and regional myocardial function for the differentiation of pathologic and physiologic left ventricular hypertrophy: a study in athletes and in patients with hypertrophic cardiomyopathy. Int. J. Cardiovasc. Imaging 27: 91-100. [Medline] [CrossRef]

6. Carasso, S., Yang, H., Woo, A., Jamorski, M., Wigle, E. D. and Rakowski, H. 2010. Diastolic myocardial mechanics in hypertrophic cardiomyopathy. J. Am. Soc. Echocardiogr. 23: 164-171. [Medline] [CrossRef]

7. Carlos Sampedrano, C., Chetboul, V., Gouni, V., Nicolle, A. P., Pouchelon, J. L. and Tissier, R. 2006. Systolic and diastolic myocardial dysfunction in cats with hypertrophic cardiomyopathy or systemic hypertension. J. Vet. Intern. Med. 20: 1106-1115. [Medline] [CrossRef]

8. Carlos Sampedrano, C., Chetboul, V., Mary, J., Tissier, R., Abitbol, M., Serres, F., Gouni, V., Thomas, A. and Pouchelon, J. L. 2009. Prospective echocardiographic and tissue Doppler imaging screening of a population of Maine Coon cats tested for the $\mathrm{A} 31 \mathrm{P}$ mutation in the myosin-binding protein $\mathrm{C}$ gene: $\mathrm{a}$ specific analysis of the heterozygous status. J. Vet. Intern. Med. 23: 91-99. [Medline] [CrossRef]

9. Chetboul, V., Sampedrano, C. C., Gouni, V., Nicolle, A. P. and Pouchelon, J. L. 2006. Two-dimensional color tissue Doppler imaging detects myocardial dysfunction before occurrence of hypertrophy in a young Maine Coon cat. Vet. Radiol. Ultrasound 47: 295-300. [Medline] [CrossRef]

10. Chetboul, V., Serres, F., Gouni, V., Tissier, R. and Pouchelon, J. L. 2007. Radial strain and strain rate by two-dimensional speckle tracking echocardiography and the tissue velocity based technique in the dog. J. Vet. Cardiol. 9: 69-81. [Medline] [CrossRef]

11. Chetboul, V., Serres, F., Gouni, V., Tissier, R. and Pouchelon, J. L. 2008. Noninvasive assessment of systolic left ventricular torsion by 2 -dimensional speckle tracking imaging in the awake dog: repeatability, reproducibility, and comparison with tissue Doppler imaging variables. J. Vet. Intern. Med. 22: 342-350. [Medline] [CrossRef]

12. Chetboul, V., Sampedrano, C. C., Tissier, R., Gouni, V., Nicolle, A. P. and Pouchelon, J. L. 2005. Reference range values of regional left ventricular myocardial velocities and time intervals assessed by tissue Doppler imaging in young nonsedated Maine Coon cats. Am. J. Vet. Res. 66: 1936-1942. [Medline] [CrossRef]

13. Chetboul, V., Sampedrano, C. C., Tissier, R., Gouni, V., Saponaro, V., Nicolle, A. P. and Pouchelon, J. L. 2006. Quantitative assessment of velocities of the annulus of the left atrioventricular valve and left ventricular free wall in healthy cats by use of two-dimensional color tissue Doppler imaging. Am. J. Vet. Res. 67: 250-258. [Medline] [CrossRef]

14. Chetboul, V., Concordet, D., Pouchelon, J. L., Athanassiadis,
N., Muller, C., Benigni, L., Munari, A. C. and Lefebvre, H. P. 2003. Effects of inter- and intra-observer variability on echocardiographic measurements in awake cats. J. Vet. Med. A Physiol. Pathol. Clin. Med. 50: 326-331. [Medline] [CrossRef]

15. Chetboul, V., Athanassiadis, N., Concordet, D., Nicolle, A., Tessier, D., Castagnet, M., Pouchelon, J. L. and Lefebvre, H. P. 2004. Observer-dependent variability of quantitative clinical endpoints: the example of canine echocardiography. J. Vet. Pharmacol. Ther. 27: 49-56. [Medline] [CrossRef]

16. Chetboul, V., Athanassiadis, N., Carlos, C., Nicolle, A. P., Tissier, R., Pouchelon, J. L., Concordet, D. and Lefebvre, H. P. 2004. Quantification, repeatability, and reproducibility of feline radial and longitudinal left ventricular velocities by tissue Doppler imaging. Am. J. Vet. Res. 65: 566-572. [Medline] [CrossRef]

17. Chetboul, V., Petit, A., Gouni, V., Trehiou-Sechi, E., Misbach, C., Balouka, D., Carlos Sampedrano, C., Pouchelon, J. L., Tissier, R. and Abitbol, M. 2012. Prospective echocardiographic and tissue Doppler screening of a large Sphynx cat population: reference ranges, heart disease prevalence and genetic aspects. $J$. Vet. Cardiol. 14: 497-509. [Medline] [CrossRef]

18. Correia, E., Rodrigues, B., Santos, L. F., Moreira, D., Gama, P., Cabral, C. and Santos, O. 2011. Longitudinal left ventricular strain in hypertrophic cardiomyopathy: correlation with nonsustained ventricular tachycardia. Echocardiography 28: 709-714. [Medline] [CrossRef]

19. Delgado, V., Ypenburg, C., van Bommel, R. J., Tops, L. F., Mollema, S. A., Marsan, N. A., Bleeker, G. B., Schalij, M. J. and Bax, J. J. 2008. Assessment of left ventricular dyssynchrony by speckle tracking strain imaging comparison between longitudinal, circumferential, and radial strain in cardiac resynchronization therapy. J. Am. Coll. Cardiol. 51: 1944-1952. [Medline] [CrossRef]

20. Drourr, L., Lefbom, B. K., Rosenthal, S. L. and Tyrrell, W. D. Jr. 2005. Measurement of M-mode echocardiographic parameters in healthy adult Maine Coon cats. J. Am. Vet. Med. Assoc. 226: 734-737. [Medline] [CrossRef]

21. Ferasin, L., Sturgess, C. P., Cannon, M. J., Caney, S. M., Gruffydd-Jones, T. J. and Wotton, P. R. 2003. Feline idiopathic cardiomyopathy: a retrospective study of 106 cats (1994-2001). J. Feline Med. Surg. 5: 151-159. [Medline] [CrossRef]

22. Fox, P. R. 2003. Hypertrophic cardiomyopathy. Clinical and pathologic correlates. J. Vet. Cardiol. 5: 39-45. [Medline] [CrossRef]

23. Fox, P. R., Liu, S. K. and Maron, B. J. 1995. Echocardiographic assessment of spontaneously occurring feline hypertrophic cardiomyopathy. An animal model of human disease. Circulation 92: 2645-2651. [Medline] [CrossRef]

24. Garceau, P., Carasso, S., Woo, A., Overgaard, C., Schwartz, L. and Rakowski, H. 2012. Evaluation of left ventricular relaxation and filling pressures in obstructive hypertrophic cardiomyopathy: comparison between invasive hemodynamics and twodimensional speckle tracking. Echocardiography 29: 934-942. [Medline] [CrossRef]

25. Golden, A. L. and Bright, J. M. 1990. Use of relaxation half-time as an index of ventricular relaxation in clinically normal cats and cats with hypertrophic cardiomyopathy. Am. J. Vet. Res. 51: 1352-1356. [Medline]

26. Granström, S., Godiksen, M. T., Christiansen, M., Pipper, C. B., Willesen, J. L. and Koch, J. 2011. Prevalence of hypertrophic cardiomyopathy in a cohort of British Shorthair cats in Denmark. J. Vet. Intern. Med. 25: 866-871. [Medline] [CrossRef]

27. Granström, S., Pipper, C. B., Mogelvang, R., Sogaard, P., Willesen, J. L. and Koch, J. 2012. Effect of sample volume size and sampling method on feline longitudinal myocardial velocity 
profiles from color tissue Doppler imaging. J. Vet. Cardiol. 14: 479-488. [Medline] [CrossRef]

28. Kato, T. S., Noda, A., Izawa, H., Yamada, A., Obata, K., Nagata, K., Iwase, M., Murohara, T. and Yokota, M. 2004. Discrimination of nonobstructive hypertrophic cardiomyopathy from hypertensive left ventricular hypertrophy on the basis of strain rate imaging by tissue Doppler ultrasonography. Circulation 110: 3808-3814. [Medline] [CrossRef]

29. Kittleson, M. D., Meurs, K. M., Munro, M. J., Kittleson, J. A., Liu, S. K., Pion, P. D. and Towbin, J. A. 1999. Familial hypertrophic cardiomyopathy in maine coon cats: an animal model of human disease. Circulation 99: 3172-3180. [Medline] [CrossRef]

30. Kobayashi, T., Popovic, Z., Bhonsale, A., Smedira, N. G., Tan, C., Rodriguez, E. R., Thamilarasan, M., Lytle, B. W., Lever, H. M. and Desai, M. Y. 2013. Association between septal strain rate and histopathology in symptomatic hypertrophic cardiomyopathy patients undergoing septal myectomy. Am. Heart J. 166: 503-511. [Medline] [CrossRef]

31. Koffas, H., Dukes-McEwan, J., Corcoran, B. M., Moran, C. M., French, A., Sboros, V., Simpson, K. and McDicken, W. N. 2006. Pulsed tissue Doppler imaging in normal cats and cats with hypertrophic cardiomyopathy. J. Vet. Intern. Med. 20: 65-77. [Medline] [CrossRef]

32. MacDonald, K. A., Kittleson, M. D., Kass, P. H. and Meurs, K. M. 2007. Tissue Doppler imaging in Maine Coon cats with a mutation of myosin binding protein $\mathrm{C}$ with or without hypertrophy. J. Vet. Intern. Med. 21: 232-237. [Medline] [CrossRef]

33. Mor-Avi, V., Lang, R. M., Badano, L. P., Belohlavek, M., Cardim, N. M., Derumeaux, G., Galderisi, M., Marwick, T., Nagueh, S. F., Sengupta, P. P., Sicari, R., Smiseth, O.A., Smulevitz, B., Takeuchi, M., Thomas, J.D., Vannan, M., Voigt, J. U. and Zamorano, J. L. 2011. Current and evolving echocardiographic techniques for the quantitative evaluation of cardiac mechanics: ASE/EAE consensus statement on methodology and indications endorsed by the Japanese Society of Echocardiography. Eur. J. Echocardiogr. 12: 167-205. [Medline] [CrossRef]

34. Mottet, E., Amberger, C., Doherr, M. G. and Lombard, C. 2012. Echocardiographic parameters in healthy young adult Sphynx cats. Schweiz. Arch. Tierheilkd. 154: 75-80. [Medline] [CrossRef]

35. Nagueh, S. F., Kopelen, H. A., Lim, D. S., Zoghbi, W. A., Quinones, M. A., Roberts, R. and Marian, A. J. 2000. Tissue Doppler imaging consistently detects myocardial contraction and relaxation abnormalities, irrespective of cardiac hypertrophy, in a transgenic rabbit model of human hypertrophic cardiomyopathy. Circulation 102: 1346-1350. [Medline] [CrossRef]

36. Nagueh, S. F., Bachinski, L. L., Meyer, D., Hill, R., Zoghbi, W. A., Tam, J. W., Quinones, M. A., Roberts, R. and Marian, A. J. 2001. Tissue Doppler imaging consistently detects myocardial abnormalities in patients with hypertrophic cardiomyopathy and provides a novel means for an early diagnosis before and independently of hypertrophy. Circulation 104: 128-130. [Medline] [CrossRef]

37. Paige, C. F., Abbott, J. A., Elvinger, F. and Pyle, R. L. 2009. Prevalence of cardiomyopathy in apparently healthy cats. $J$. Am. Vet. Med. Assoc. 234: 1398-1403. [Medline] [CrossRef]

38. Popović, Z. B., Kwon, D. H., Mishra, M., Buakhamsri, A., Greenberg, N. L., Thamilarasan, M., Flamm, S. D., Thomas, J. D., Lever, H. M. and Desai, M. Y. 2008. Association between regional ventricular function and myocardial fibrosis in hypertrophic cardiomyopathy assessed by speckle tracking echocardiography and delayed hyperenhancement magnetic resonance imaging. J. Am. Soc. Echocardiogr. 21: 1299-1305. [Medline] [CrossRef]

39. Saito, M., Okayama, H., Yoshii, T., Higashi, H., Morioka, H.,
Hiasa, G., Sumimoto, T., Inaba, S., Nishimura, K., Inoue, K., Ogimoto, A., Shigematsu, Y., Hamada, M. and Higaki, J. 2012. Clinical significance of global two-dimensional strain as a surrogate parameter of myocardial fibrosis and cardiac events in patients with hypertrophic cardiomyopathy. Eur. Heart J. Cardiovasc. Imaging 13: 617-623. [Medline] [CrossRef]

40. Serri, K., Reant, P., Lafitte, M., Berhouet, M., Le Bouffos, V., Roudaut, R. and Lafitte, S. 2006. Global and regional myocardial function quantification by two-dimensional strain: application in hypertrophic cardiomyopathy. J. Am. Coll. Cardiol. 47: 1175-1181. [Medline] [CrossRef]

41. Silva, A. C., Muzzi, R. A., Oberlender, G., Nogueira, R. B., Muzzi, L. A., Reis, G. F. and Mantovani, M. M. 2013. Longitudinal strain and strain rate by two-dimensional speckle tracking in non-sedated healthy cats. Res. Vet. Sci. 95: 1175-1180. [Medline] [CrossRef]

42. Simpson, K. E., Gunn-Moore, D. A., Shaw, D. J., French, A. T., Dukes-McEwan, J., Moran, C. M. and Corcoran, B. M. 2009. Pulsed-wave Doppler tissue imaging velocities in normal geriatric cats and geriatric cats with primary or systemic diseases linked to specific cardiomyopathies in humans, and the influence of age and heart rate upon these velocities. J. Feline Med. Surg. 11: 293-304. [Medline] [CrossRef]

43. Simpson, K. E., Devine, B. C., Gunn-Moore, D. A., French, A. T., Dukes-McEwan, J., Koffas, H., Moran, C. M. and Corcoran, B. M. 2007. Assessment of the repeatability of feline echocardiography using conventional echocardiography and spectral pulse-wave Doppler tissue imaging techniques. Vet. Radiol. Ultrasound 48: 58-68. [Medline] [CrossRef]

44. Sutherland, G. R., Stewart, M. J., Groundstroem, K. W., Moran, C. M., Fleming, A., Guell-Peris, F. J., Riemersma, R. A., Fenn, L. N., Fox, K. A. and McDicken, W. N. 1994. Color Doppler myocardial imaging: a new technique for the assessment of myocardial function. J. Am. Soc. Echocardiogr. 7: 441-458. [Medline] [CrossRef]

45. Trehiou-Sechi, E., Tissier, R., Gouni, V., Misbach, C., Petit, A. M., Balouka, D., Sampedrano, C. C., Castaignet, M., Pouchelon, J. L. and Chetboul, V. 2012. Comparative echocardiographic and clinical features of hypertrophic cardiomyopathy in 5 breeds of cats: a retrospective analysis of 344 cases (2001-2011). J. Vet. Intern. Med. 26: 532-541. [Medline] [CrossRef]

46. van Dalen, B. M., Bosch, J. G., Kauer, F., Soliman, O. I., Vletter, W. B., ten Cate, F. J. and Geleijnse, M. L. 2009. Assessment of mitral annular velocities by speckle tracking echocardiography versus tissue Doppler imaging: validation, feasibility, and reproducibility. J. Am. Soc. Echocardiogr. 22: 1302-1308. [Medline] [CrossRef]

47. Wess, G., Sarkar, R. and Hartmann, K. 2010. Assessment of left ventricular systolic function by strain imaging echocardiography in various stages of feline hypertrophic cardiomyopathy. $J$. Vet. Intern. Med. J. Vet. Intern. Med. 24: 1375-1382. [Medline] [CrossRef]

48. Wess, G., Keller, L. J., Klausnitzer, M., Killich, M. and Hartmann, K. 2011. Comparison of longitudinal myocardial tissue velocity, strain, and strain rate measured by two-dimensional speckle tracking and by color tissue Doppler imaging in healthy dogs. J. Vet. Cardiol. 13: 31-43. [Medline] [CrossRef]

49. Zois, N. E., Tidholm, A., Nagga, K. M., Moesgaard, S. G., Rasmussen, C. E., Falk, T., Haggstrom, J., Pedersen, H. D., Ablad, B., Nilsen, H. Y. and Olsen, L. H. 2012. Radial and longitudinal strain and strain rate assessed by speckle-tracking echocardiography in dogs with myxomatous mitral valve disease. J. Vet. Intern. Med. 26: 1309-1319. [Medline] [CrossRef] 